\title{
Temporal variations in microclimate cooling induced by urban trees in Mainz, Germany
}

\author{
Jenny Lindén ${ }^{1}$, Patrick Fonti ${ }^{2}$, Jan Esper ${ }^{1}$ \\ 1. Department of Geography, Johannes-Gutenberg University, Mainz, Germany \\ 2. Swiss Federal Research Institute WSL, Birmensdorf, Switzerland
}

\begin{abstract}
Global warming is likely to increase the frequency and magnitude of heat waves. As the urban geometry and material amplifies warming, city dwellers will face an intensification of heat-induced health problems and mortality. Although increased vegetation cover is frequently used in urban planning to mitigate excessive heat, temporal variations, as well as the influence of synoptic weather conditions and surrounding urban geometry on the vegetation cooling effect, are still unclear. In this study, we monitored the transpiration-induced cooling from trees over two summers in five urban settings characterized by varying levels of greenness and urban geometry in the city of Mainz (Germany). Differences in air temperature and humidity patterns were compared with estimates of tree transpiration derived from high-resolution stem size and sap flow measurements. Results from the five urban sites indicate significant cooling due to transpiration, but with large variability depending on time of day and weather conditions. The cooling effect is strongest during periods of high transpiration demand, and in the stable nocturnal boundary layer when air mixing is limited. The strongest transpiration cooling was found in an enclosed courtyard structure. These findings reveal that a few trees can substantially mitigate urban excess heat, but that the urban geometry, time of the day, and prevailing weather conditions considerably modulate this effect.
\end{abstract}

This document is the accepted manuscript version of the following article:

Lindén, J., Fonti, P., \& Esper, J. (2016). Temporal variations in microclimate cooling induced by urban trees in Mainz, Germany. Urban Forestry and Urban Greening, 20, 198-209. https://doi.org/10.1016/j.ufug.2016.09.001

This manuscript version is made available under the CC-BY-NC-ND 4.0

license http://creativecommons.org/1icenses/by-nc-nd/4.0/ 


\section{Introduction}

Heat-related health problems and mortality are expected to rise, as global warming is projected to cause more frequent and stronger heat waves (IPCC 2014). City dwellers in particular are at risk because of the urban heat island (UHI) effect, i.e. the intensified warming caused by altered land surface properties. These modifications include an increased thermal admittance of construction materials, the restricted radiative and advective cooling due to the urban geometry, and the lowered evapotranspiration-induced cooling due to sealed surfaces and limited vegetation coverage (e.g. Arnfield 2003; Oke 1987). The UHl effect is strongest at night, causing a lack of adequate nocturnal relief from heat stress for the urban inhabitants which has been linked to, for example, increased urban mortality during heat waves (Clarke 1972; Conti et al. 2005). Appropriate urban planning is thus required to mitigate the warming effects in cities. One key approach used is to increase the abundance of vegetation (Bowler et al. 2011; Norton et al. 2015; Taha 1997) which lowers temperatures and improves the human thermal comfort, particularly during heat waves (Harlan et al. 2006).

The cooling effect of vegetation includes shading and evapotranspiration (e.g. Bowler et al. 2011). Shading from urban trees reduces heating of surfaces and depends on the three dimensional shape and the degree of vegetation permeability to solar radiation (Konarska et al. 2014). While shading can considerably increase human comfort, its effect on air temperature (TA) appears limited (Oliveira et al. 2011). More efficient for TA is the cooling by transpiration, whereby the water that transpires during the process of photosynthesis transfers sensible heat into latent (Grimmond and Oke 1991; Taha 1997). Slightly lower air temperatures have been found over grassy urban surfaces than above concrete (e.g. Mueller and Day 2005). Lower air temperatures above green roofs has also been found but effect is small and very variable (e.g. Wong et al. 2003) A review by Qiu et al (2013) showed that transpiration, especially from taller vegetation in parks can reduce urban temperatures between 0.5 and $4{ }^{\circ} \mathrm{C}$, with time and magnitude for maximum influence depending on park type, size, and climate. Hamada and Ohta (2010) also noted an important transpiration induced cooling from urban parks in summer, but stated that further studies are needed to clarify the physiological effects influencing the transpiration of urban vegetation. Street trees were found to have very strong transpiration compared to urban trees in other settings in a study by Pataki et al (2011), but the transpiration-induced cooling from isolated trees in streets and other urban settings remain largely unknown. The rate of transpiration generally increases with atmospheric evaporative demand (often expressed as the vapour pressure deficit, VPD, Eamus et al. 2013) and depends on water availability. The influence of VPD also depend on the wood anatomy where diffuse porous taxa showed a near linear increase in transpiration with VPD (Bush et al. 2008). By using highresolution measurements of stem size changes, King et al (2013) showed that both meteorological conditions and soil water availability impact the diurnal cycle of tree-water relations. However, these relations are only valid as long as enough water is available in the soils (Brodribb and Holbrook 2004; Gao et al. 2002; Gindaba et al. 2004; Ma et al. 2004; Zweifel et al. 2001).

Although numerous studies of urban climate have shown that cooler places within the city are closely connected to an increased vegetation cover (Alavipanah et al. 2015; Fan et al. 2015; Harlan et al. 2006; Lindén 2011; Middel et al. 2012; Norton et al. 2015), the diurnal variations as well as influence of changing weather 
54 conditions on the transpiration-induced cooling are still unclear. For example, cooling was strongest in the

55 afternoon in irrigated parks and parks in humid climates (Jonsson 2004; Potchter et al. 2006; Spronken-Smith

56 and Oke 1998). However, a review by (Bowler et al. 2011) showed that cooling from urban green spaces is in

57 general slightly stronger at nighttime and nocturnal effects also dominated in non-irrigated parks in e.g.

58 Ouagadougou, Sacramento, and Vancouver (Lindén 2011; Spronken-Smith and Oke 1998).

59 Here we evaluate the effectiveness of transpiration-induced cooling from trees by comparing urban climate

60 among sites with contrasting greenness and urban geometry. In particular, we aim to (1) quantify differences

61 in seasonal and diurnal patterns of temperature and humidity among urban sites, (2) link these differences to

62 tree transpiration as derived from continuous measurements of sap flow (SF) and stem size variations, and (3)

63 examine the influence of atmospheric evaporative demand and extreme drought stress on the transpiration-

64 induced cooling processes.

65

\section{Methods}

\subsection{Study sites}

68 The study has been performed in the city of Mainz in Germany (50.0 $\mathrm{N}, 8^{\circ} 3^{\circ} \mathrm{E}$, elevation 100 m.a.s.l, Fig. 1).

69 Mainz is an inland city with approximately 200000 inhabitants, located in a landscape of gently rolling hills on 70 the western side of the Rhine River. The climate is temperate and humid with an annual average TA of $10.7^{\circ} \mathrm{C}$ 71 and precipitation of $620 \mathrm{~mm}$. The summers are warm and humid (June to August: $19.2^{\circ} \mathrm{C}$ and $175 \mathrm{~mm}$, from 72 1981-2010, www.dwd.de). The city architecture has a compact midrise structure (Stewart and Oke 2012) with 73 smaller parks, grassy areas, and streets with scattered trees. Soil conditions for the urban sites are varying and heavily disturbed since most structures were built on top of the rubble from the second world war. 

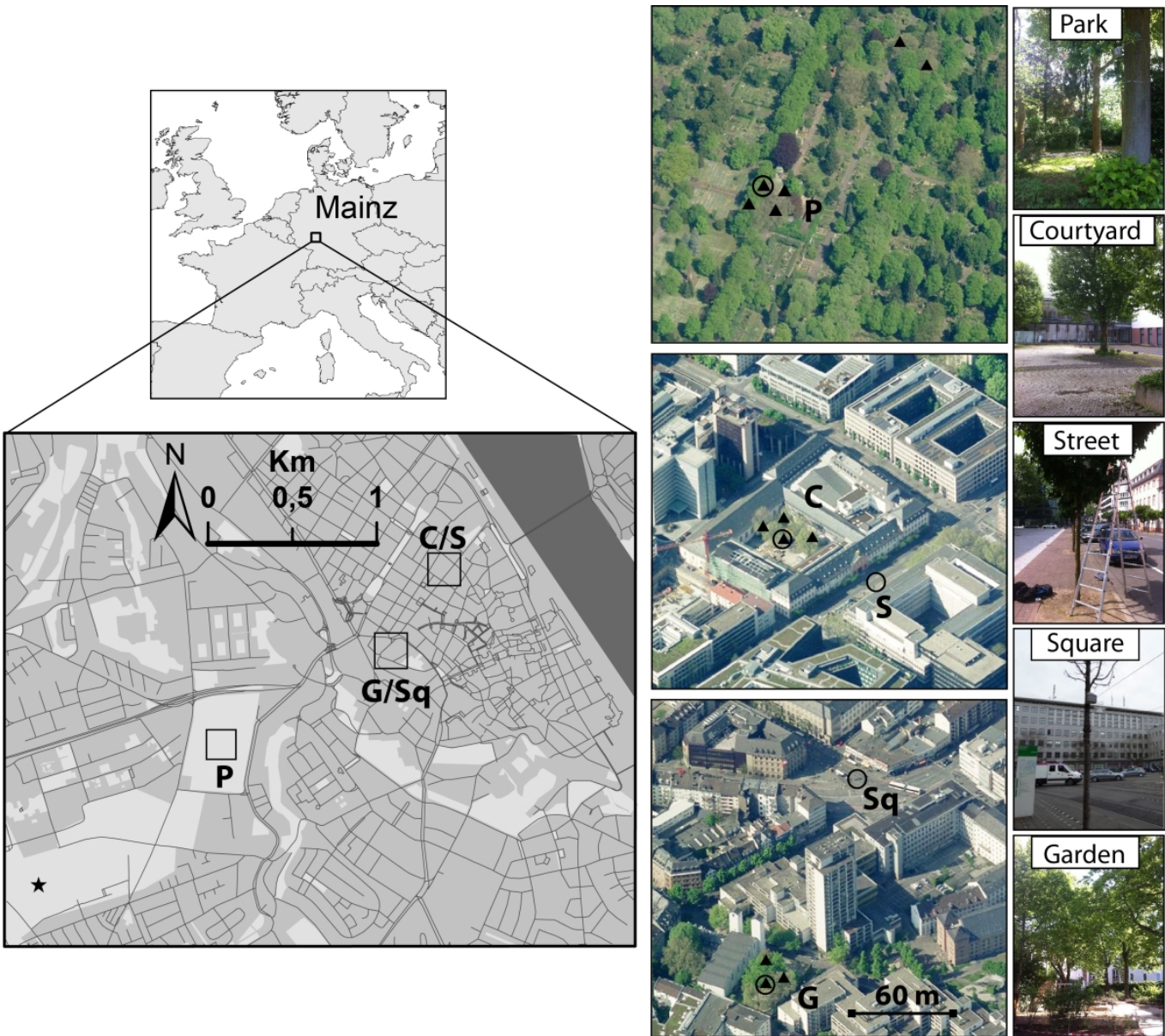

Figure 1. The city Mainz and locations of monitored sites in the Park (P), Courtyard (C), Street (S), Garden (G), and Square (Sq). Air temperature and humidity measurements marked with circles, monitored trees marked with triangles, and synoptic met station location marked with star. Birds-eye images are from Bing maps (www.bing.com/maps). 
81 Table 1. Description of the sites, and of the trees and climate parameters monitored. Vegetation cover within a radius of $50 \mathrm{~m}$ around the site center. LCZ according to 82 Stewart and Oke 2012

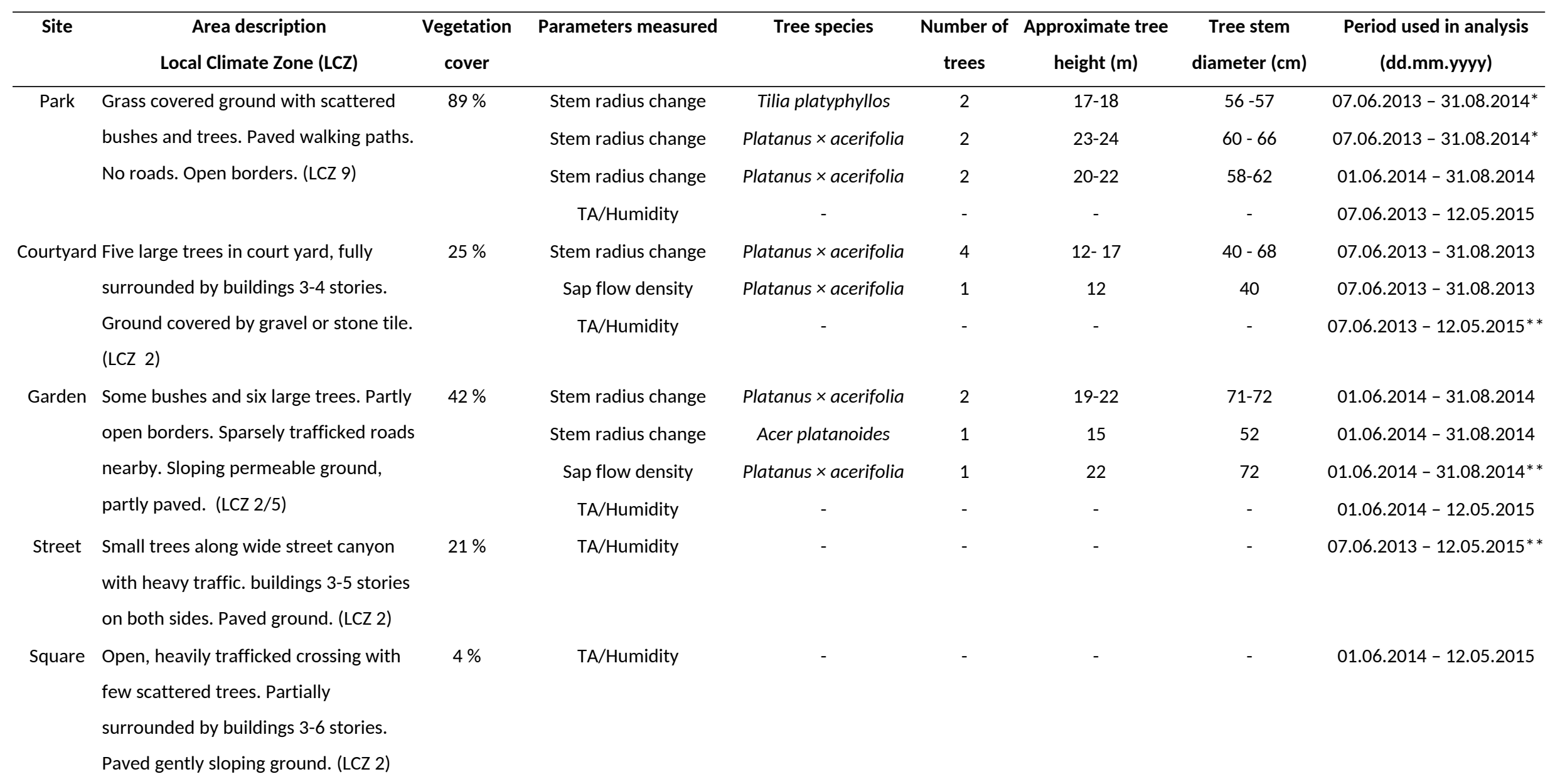

$84{ }^{*}$ Data analysed only for the two summer periods; June, July and August 2013 and 2014

$85^{* *}$ Shorter data gap due to technical problems 
Five sites varying in vegetation cover and building structure were selected: one suburban park of sparsely built structure according to the local climate zone (LCZ) categorization (Stewart and Oke 2012) as well as four urban sites with different levels of greenness (with and without trees) and architectural geometry (LCZ 2 and 5) were selected (Tab. 1). The sub-urban forested park (hereafter Park) was chosen as a site representative of high level of greenness. The two vegetated urban sites with some mature trees but with different geometry (a closed Courtyard and an open Garden) represent the urban structure of Mainz. These were both coupled with adjacent open and sparsely vegetated urban elements (a Street and a Square, Fig. 1). Information about area average sky view factor for each site was not possible to obtain in this study, and the sites are instead described in view of vegetation cover within $30 \mathrm{~m}$ of the center of the area, with surrounding building structure and activity described in text (Tab. 1). Land cover within a similar distance was found to be most important for microclimate differences by Konarska et al (2016). For the Park, Courtyard and Garden sites, Platanus $\times$ acerifolia was chosen for measurement of stem radius change and Sap Flow where available, with addition of two Tilia platyphyllos in the Park, and one Acer platanoides in the Garden (where only two Platanus $x$ acerifolia were available). The trees in Mainz start foliating in the beginning of April and appeared fully foliated in the beginning of June when measurements of sap flow and stem radius were initiated. The canopies of Platanus $\times$ acerifolia were very dense with large leaves (around $300 \mathrm{~cm}^{2}$ ) in the urban sites, especially in the courtyard where pruning had taken place in 2011, and less dense in the park where trees were allowed to grow freely. Canopies of Tilia platyphyllos were also dense, while Acer platanoides was less dense. 2013 and 2014 started out similar, but in 2013 the leaves started going partly brown in the beginning of August, likely due to the warmer and drier conditions this summer. Leaf area density was not measured in this study but has previously been found to vary between 0.3 and 0.5 for unpruned Platanus $\times$ acerifolia (Hipps et al. 2014). Platanus $\times$ acerifolia has in a previous study shown a near linear increase in transpiration with VPD (Bush et al. 2008).

\subsection{Monitored parameters}

Spatial and temporal variations in climate and tree transpiration were assessed at a temporal resolution of 30 minutes during different periods between June 2013 and February 2015 (Tab. 1). The measurements were performed over the full period at the Park site, but the coupled urban elements were monitored during only one summer, i.e. the Courtyard-Street in 2013 and the Garden-Square in 2014. However, the climate sensors have been kept running during the whole period in the Courtyard-Street sites and for one year in the Garden Square sites to support comparisons of seasonal patterns.

The climate was monitored at all sites by measuring TA and relative humidity (HR) using HOBO U23-001 Pro v2 data loggers placed in RS1 solar radiation shields (Onset, Bourne, MA, USA), at a height of approximately $3 \mathrm{~m}$ to avoid vandalism. This type of sensor and shielding was found to be the most reliable in comparison to other types of shielding (Da Cunha 2015). One sensor per site was used. As commonly found in urban areas, standard guidelines for placement of meteorological instruments was not possible to follow due to the complexity of the selected study sites, but recommendations in the WMO guidelines for urban climate studies 
122 (Oke 2008) were carefully followed when selecting sensor placement to minimize any potential bias. Due to

123 urban activity and traffic, posts for sensor installation could not be installed. Existing posts were of different

124 size and material, and placed at varying distance from the walls and the HOBO-sensors were instead placed on

125 tree stems or branches on the north side of the tree, where a free airflow around the sensor could be ensured

126 (no leaves or dense branch structure nearby). This placement reduces the risk of temperature bias from

127 nearby heated walls and other anthropogenic materials, and as the microclimate influence of trees is the focus

128 of the study, any potential influence caused by differences in canopy geometry of the sensor trees was

129 determined to be small and seen as part of the aim.

130 Prior to installation, a comparison among the sensors located in a well ventilated rooftop for 22 days (with TA

131 ranging from $-4{ }^{\circ} \mathrm{C}$ to $18^{\circ} \mathrm{C}$ and $\mathrm{HR}$ from 30 to $100 \%$ ) showed agreement with an average difference in TA <

$132 \pm 0.08 \mathrm{~K}(<2 \%$ exceeding $\pm 0.2 \mathrm{~K})$, and in $\mathrm{HR}<0.2 \%(<2 \%$ exceeding $1 \%)$. These measurements were then used

133 to derive specific humidity (HS) and vapour pressure deficit (VPD), using equations 1-3 (e.g. Monteith and

134 Unsworth 2007):

$135 S V P=610.7 \times 10^{\left(\frac{7.5 \mathrm{TA}}{237.3+\mathrm{TA}}\right)}$

$136 \quad H S=\left(2.16679 \times \frac{H R * S V P}{100(T A+273.3)}\right) \rho^{-1}$

$137 \quad V P D=\left(1-\frac{H R}{100}\right) \times S V P$

138 Where SVP = saturation vapor pressure $(\mathrm{kPa}), \mathrm{TA}=$ air temperature $\left({ }^{\circ} \mathrm{C}\right), \mathrm{HS}=$ Specific Humidity $(\mathrm{g} / \mathrm{kg}), \mathrm{HR}=$ relative Humidity (\%), $\rho=$ density of air $\left(\mathrm{kg} / \mathrm{m}^{3}\right)$, and VPD = Vapor pressure deficit $(\mathrm{kPa})$.

140 The site data were then complemented with local measurements of precipitation, wind and solar radiation 141 from a nearby (<3 km from all sites) meteorological station at the institute of Atmospheric Physics of the 142 Johannes-Gutenberg University (Fig. 1). Accumulated precipitation over the past 20 days (PRC20) was 143 calculated to estimate drought conditions as suggested by Konarska et al (2016).

Tree transpiration was indirectly quantified by monitoring stem size variation and sap flux on mature trees in the Courtyard and Garden sites, and stem size variation in the Park site (Tab 1). These two parameters are good estimators for high-resolution water use and physiological stress. In particular, maximum daily stem shrinkage (MDS) has proved to be a good estimator for daily stem water balance (King et al, 2013). Sap flux density (SF) is used to quantify the amount of sap flowing up the stem, which is directly associated to the amount of transpired water (Granier 1987; Granier et al. 1996). Measurements of stem size variability were obtained using point dendrometers (DL-R, Ecomatik, Munich, Germany) installed on 6 trees in the Park (2 Tilia platyphyllus and 4 Platanus $x$ acerofolia), 4 trees in the Courtyard (4 Platanus $x$ acerofolia), and 3 trees in the 
using screws extending in to the heartwood to secure a highly sensitive sensor monitoring the daily

154 fluctuations in stem radius. Sap flux density data were obtained using a Granier thermal dissipation probe (SF-

155 L, Ecomatik, Munich, Germany), which make use of temperature difference between four thermocouple

156 needles (one heated needle and three needles above to measure sap ambient temperature, see (Granier

157 1987) inserted three $\mathrm{cm}$ in the sapwood. Sensors were installed on the north side of the tree stems on one

158 Platanus $x$ Acerofolia in each of the Courtyard and Garden sites. The sapwood depth of Platanus $x$ Acerofolia

159 exceeds this depth (Pataki et al. 2011), and the sap flow through the stem varies on different sides depending

160 on canopy sun exposure. Our data is therefore only used to examine the diurnal variations in sap flow and not

161 as a measure of total amount of transpired water.

\subsection{Site comparisons}

163 To examine differences in climate patterns among sites, and associate these with potential cooling effects of 164 the trees, measurements were compared among site-couples of differing degrees of greenness and location

165 within the city. The couplings include comparison between one densely vegetated park and two urban sites;

166 Park - Courtyard (P-C), and Park - Garden (P-G). To examine the microclimate differences connected to

167 transpiration, the two urban sites were also compared with nearby sites of different character (less vegetation,

168 different building structure) in the site couples Courtyard - Street (C-S), and Garden - Square (G-Sq).

169 Comparisons were performed considering different seasons (summer, autumn, winter, and spring), time of the

170 day (10:00-16:00 for daytime, and 19:00-04:00 for nighttime, times apply to all day/night analyses), and

171 demand for atmospheric evaporation. The latter has been derived from three classes of daily average VPD

172 (measured in the Park) defined as low (VPD, first $20^{\text {th }}$ percentile, VPD $\left.<0.54 \mathrm{kPa}\right)$, moderate $\left(\mathrm{VPD}_{\mathrm{M}}, 0.54<\right.$

$173 \mathrm{VPD}<1.315 \mathrm{kPa})$ and high $\left(\mathrm{VPD}_{\mathrm{H}}, 80^{\text {th }}\right.$ percentile, $\left.\mathrm{VPD}>1.315 \mathrm{kPa}\right) . \mathrm{VPD}_{\mathrm{H}}$ was further divided into 2 classes

174 based on soil water availability considering PRC20 data (VPD Hwet $>6 \mathrm{~mm}$ and $\left.\mathrm{VPD}_{\text {Hdry }}<6 \mathrm{~mm}\right)$.

175 As a target for between-site climatic differences we considered TA and HS, while daily MDS and SF were used

176 as estimates of tree transpiration. Stem radius and sap flux density data were standardized for each tree

177 related to the 95th percentile of their individual diurnal curves before an average curve for each site was

178 calculated to obtain relative terms for comparison.

\section{Results}

\subsection{Stem size variation and sap flux density responses to weather conditions} In comparison to the 1981 - 2010 average, the 2013 summer (from June to August) was $1^{\circ} \mathrm{C}$ warmer (average $20.2^{\circ} \mathrm{C}$ ) and $73 \mathrm{~mm}$ drier (precipitation sum $102 \mathrm{~mm}$ ) than the average, while the successive season was colder $\left(18.9^{\circ} \mathrm{C}\right)$, wetter $(222 \mathrm{~mm})$, and with relatively well distributed precipitation over the summer (Fig. 2). The parameters monitored on the tree stem were indicating that tree water balance was mainly responding to the daily weather conditions. The trees show considerable differences in cumulative stem size and a relative large range of MDS, likely a result of the difference in size and canopy density as well as soil conditions. 
However, the responses to changing VPD and water availability are coherent among the trees of each site. In particular, all trees showed abrupt increases in stem size in relation to precipitation events, and slightly decreasing stem size and sap flux density when there was a higher demand for transpiration under reduced condition of water availability, as for example at the beginning of August 2013.

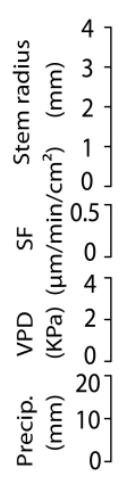

a)
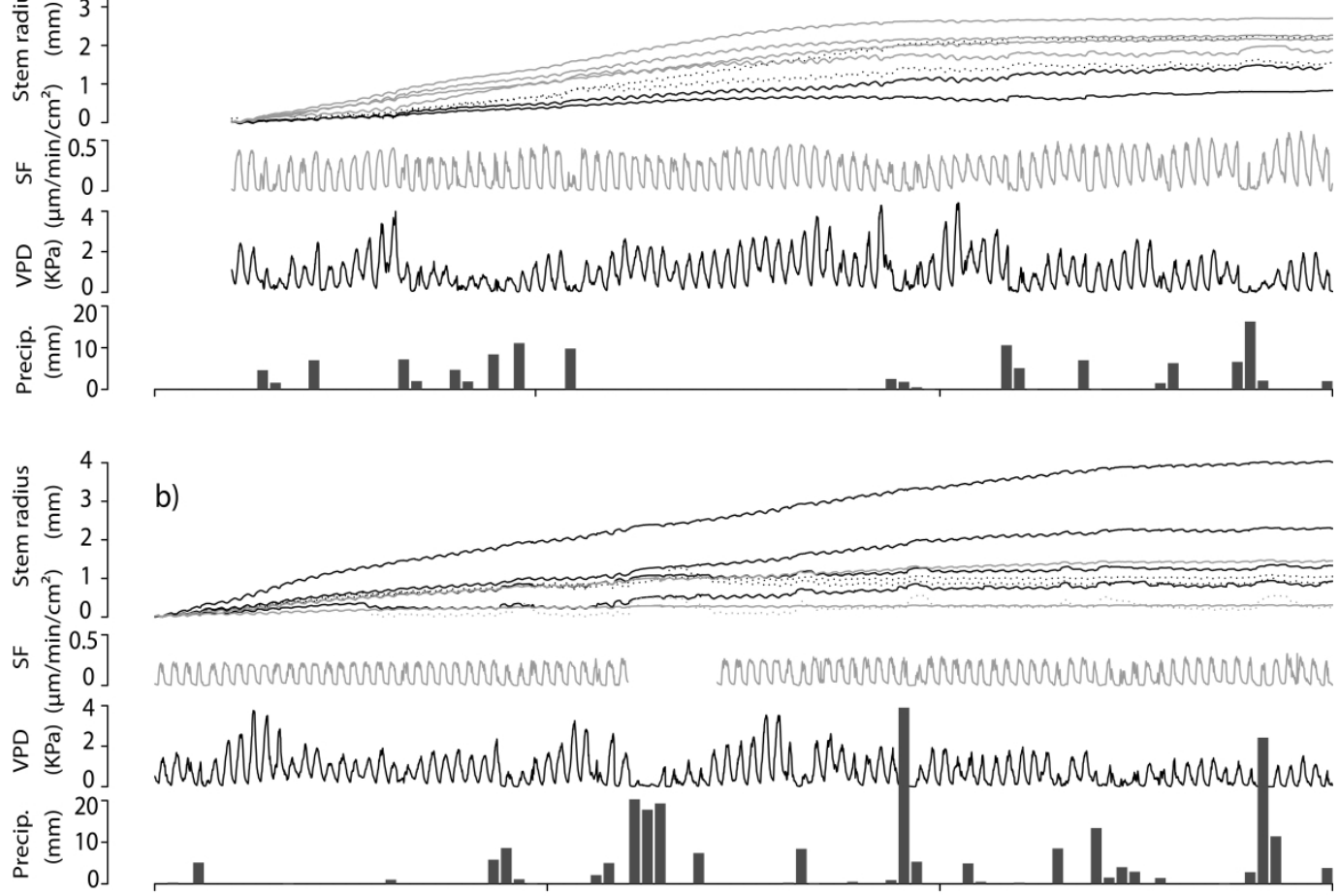

b)

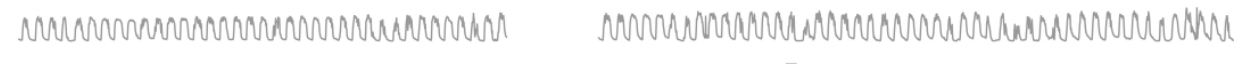

Figure 2. Absolute stem radius change, sap flux density (SF), vapour pressure deficit (VPD) and precipitation from June to October during (a) the growing seasons 2013 and (b) 2014. Grey lines indicates measurements from the Courtyard (2013) and the Garden (2014), black lines are relative to the trees and sensors in the Park. Solid lines show Platanus $\times$ acerifolia, dotted lines Tilia platyphyllus, Park; and Acer Platanoides, Garden. VPD is based on measurements of temperature and humidity in the Park, and precipitation data are from the meteo-station of the University of Mainz located less than $3 \mathrm{~km}$ away from the sites.

Influence of evaporative demand and drought on SF and MDS was examined in Figure 3. MDS increase with evaporative demand, while SF initially increase with VPD, then level out. The influence of precipitation on SF is less clear, but in the drier year 2013, the highest SF levels are measured subsequent to moderate precipitation events, and lower SF levels are recorded in very dry or very wet conditions. MDS measured in 2013 indicates that the strongest stem shrinkage occurs in dry conditions, while no connection between MDS and PRC20 was detected in 2014. The highest SF was found in the later part of the season. This pattern was found in both summers but stronger in 2013. The influence of VPD and PRC on MDS was very similar when examined for each individual tree (not shown in graph) confirming that averages for each site are representative. 

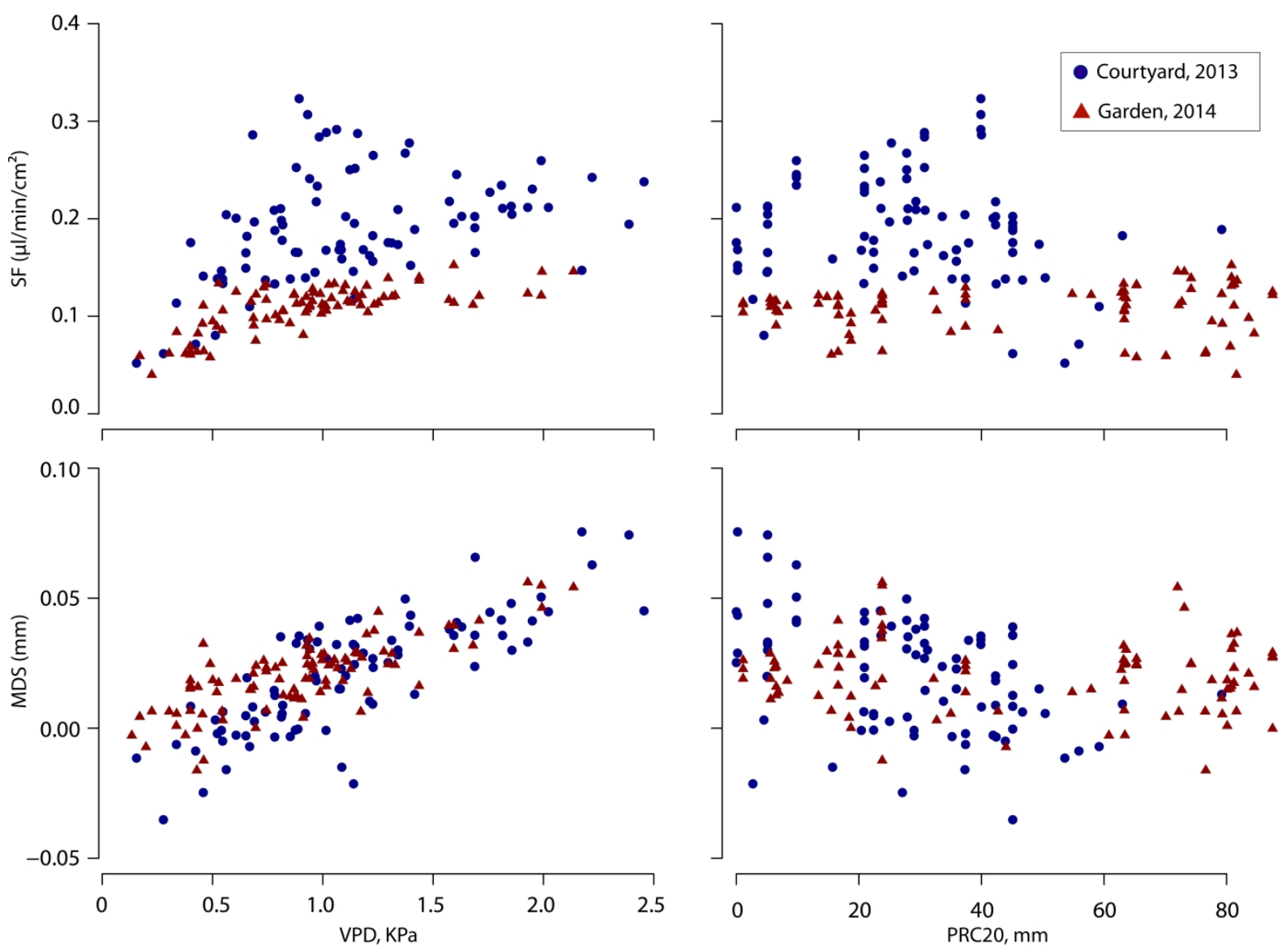

Figure 3. Scatter plots showing the relationship between average daily sap flux density (SF, top) and maximum daily stem shrinkage (MDS, bottom) versus vapour pressure deficit (VPD, left) and precipitation (right) accumulated over the past 20 days (PRC20, right). Blue circles are the measurements of SF/MDS/VPD from the Courtyard in 2013, red triangles are from the Garden in 2014. Precipitation is measured at the meteorological station.

213 The influence of evaporative demand and drought on the diurnal pattern of stem radius change and SF is shown in fig 4. Stem radius reaches a maximum around sunrise, then starts shrinking when evaporative demand causes the transpiration rate to exceed refilling rate. This continues until late afternoon, when the evaporative demand decrease and the tree stem start to expand again. The amplitude of this diurnal pattern increased with evaporative demand. Response to drought caused an increase in daily amplitude in the Park but decrease in the Courtyard. SF increases rapidly after sunrise at around 05:00, then stays high throughout the day and slowly decreases in the late afternoon. In these average curves, the level of SF equals approximately half of the daily maximum at sunset. SF equals a quarter of the daily maximum at midnight and reaches a minimum before sunrise. The average nocturnal SF in 2013/2014 were $28 / 17 \%$ of the daytime levels. The night to day ratio is highest for the category VPD $\mathrm{Hdry}_{\mathrm{y}}(33 \%)$ indicating that nocturnal transpiration is increased during dry conditions. A reduction of stem size is also visible during the daytime when transpiration exceeds refilling from the roots. This negative stem water balance continues until the transpiration loss is reduced in the late afternoon and stem radius increases again. The amplitude of the diurnal pattern in both stem radius change and SF increase with increasing VPD. The only exception was the SF during dry conditions $\left(V P D_{\text {Hdry }}\right)$ when the daily maximum was reduced. 

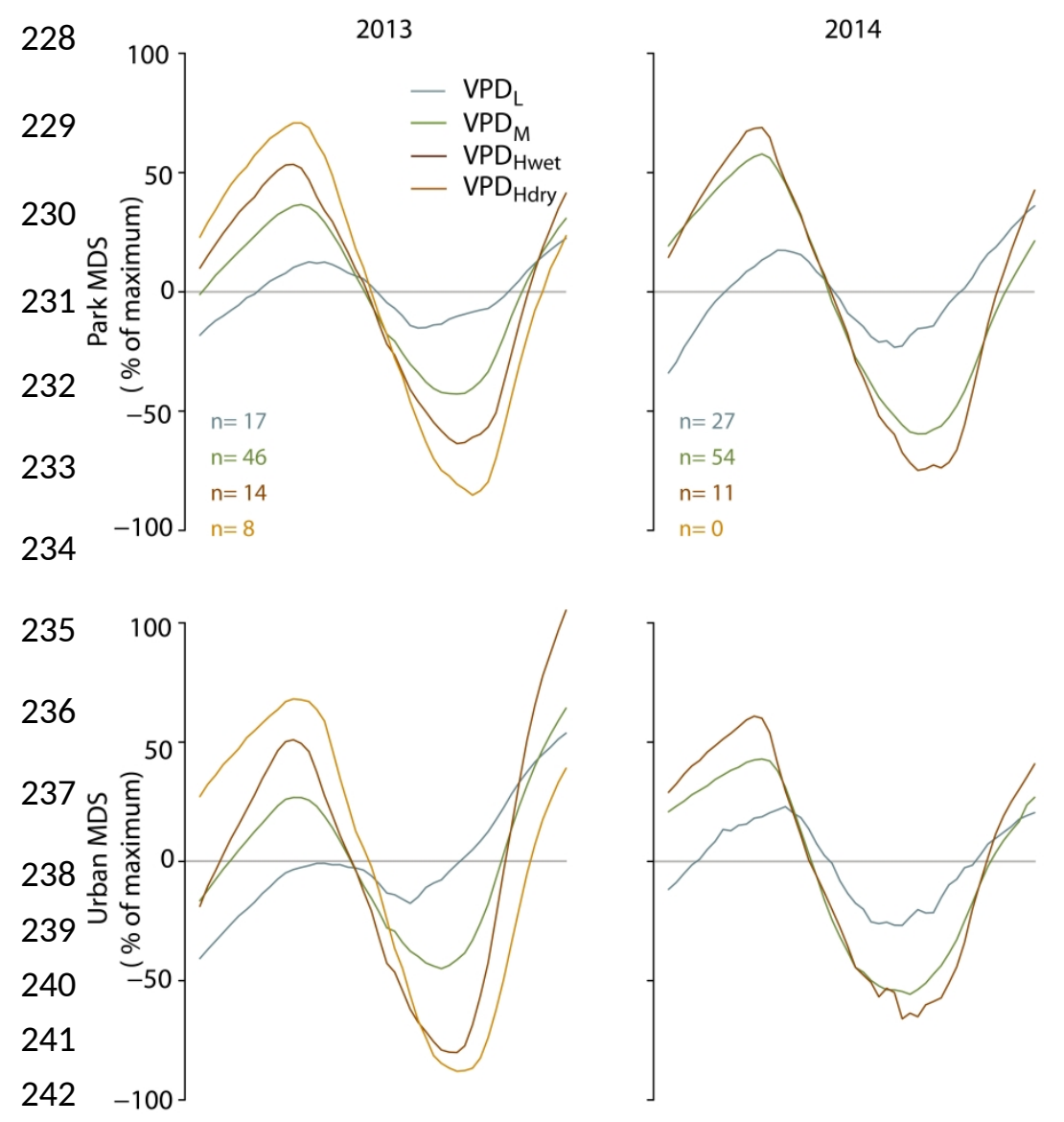

Figure 4. Standardized maximum daily stem shrinkage (MDS) and sap flux density (SF) during the summer season in the Park (2013 left, and 2014 right), Courtyard (2013, left), and Garden (2014 right) sites.

243

244

245

246

247 菂

248 穴

$249 \stackrel{\circ}{5}$ है
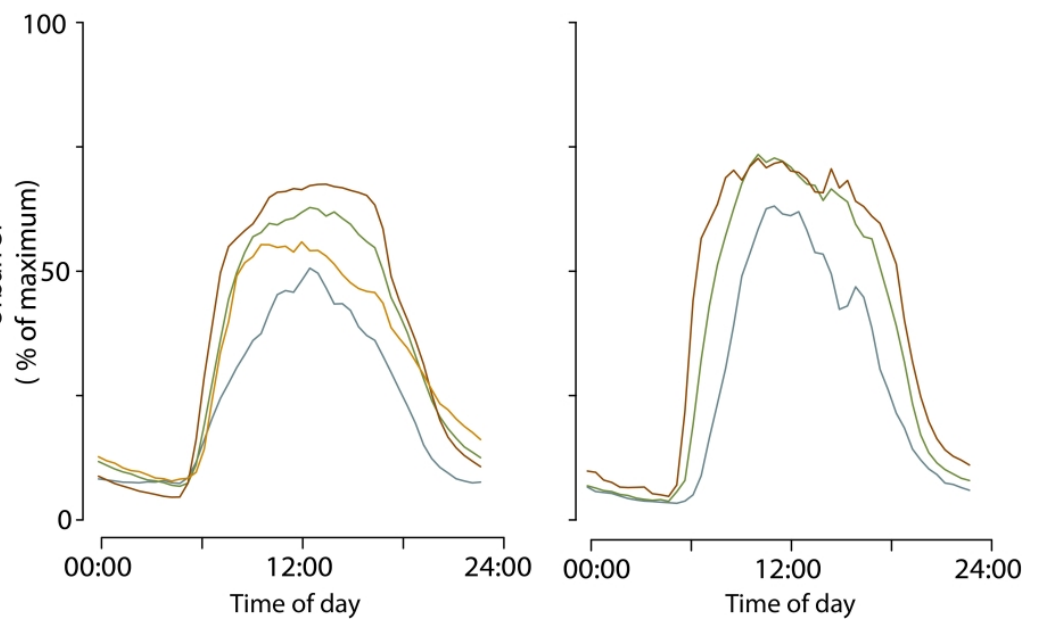
Lines show the mean values for the VPD categorized days including $\mathrm{VPD}_{\mathrm{L}}<0.68$ $\mathrm{kPa}$ (20th percentile), $\mathrm{VPD}_{\mathrm{M}}(0.68-1.4 \mathrm{kPa})$, and $\mathrm{VPD}_{\mathrm{H}}>1.4 \mathrm{kPa}$ (80th percentile). VPD days are further separated in to low $\left(\right.$ VPD $_{\text {Hwet, }}$ PRC20>6mm) and high $\left(\right.$ VPD $_{\text {Hdry, }}$ PRC20<6 mm) drought stress. $\mathrm{N}$ indicates the number of days included in each category. All times shown are CET, i.e. sunrise occurs at approximately 05:00, sunset at 20:00, and solar noon at 12:30.

256 Comparisons between the sites revealed reduced temperatures in the more vegetated areas (Fig. 5).

257 Differences were generally largest at night when the Park was 1.0/0.8 K colder than the vegetated urban areas

258 (Courtyard/Garden, median, full period), which in turn were colder than their nearby and sparsely vegetated 259 counterparts (Street and Square) by 0.2 and $0.5 \mathrm{~K}$, respectively. These differences varied among seasons, with 260 largest magnitudes in spring and summer when a maximum nocturnal urban heat island of $3.9 / 3.2 \mathrm{~K}$ was measured between the Park and the Street/Square sites. 
A comparison of the urban sites showed some deviations from the general pattern. For example, warmer daytime temperatures were found in the closed-in Courtyard compared to the open and less vegetated adjacent Street in spring $\left(\Delta \mathrm{TA}_{\mathrm{C}-\mathrm{s}}\right.$, difference of $\left.0.3 \mathrm{~K}\right)$ mainly included days before trees were foliated. The differences diminished and eventually turned opposite during the summer and autumn when trees were fully foliated. Deviating patterns were also found between the vegetated Garden and the adjacent open Square partially surrounded by buildings $\left(\Delta \mathrm{TA}_{\mathrm{G}-\mathrm{sq}}\right)$, where daytime differences always exceeded nighttime differences. While humidity was generally higher in the more vegetated sites, both the Courtyard and the Garden sites showed similar, and in autumn even higher, nighttime humidity levels compared to the Park. The courtyard was more humid compared to the Street at night in the foliated summer and autumn period, but slightly less humid in winter and spring, and the Garden was surprisingly less humid than the Square at all times and seasons, except for summer daytimes.

273
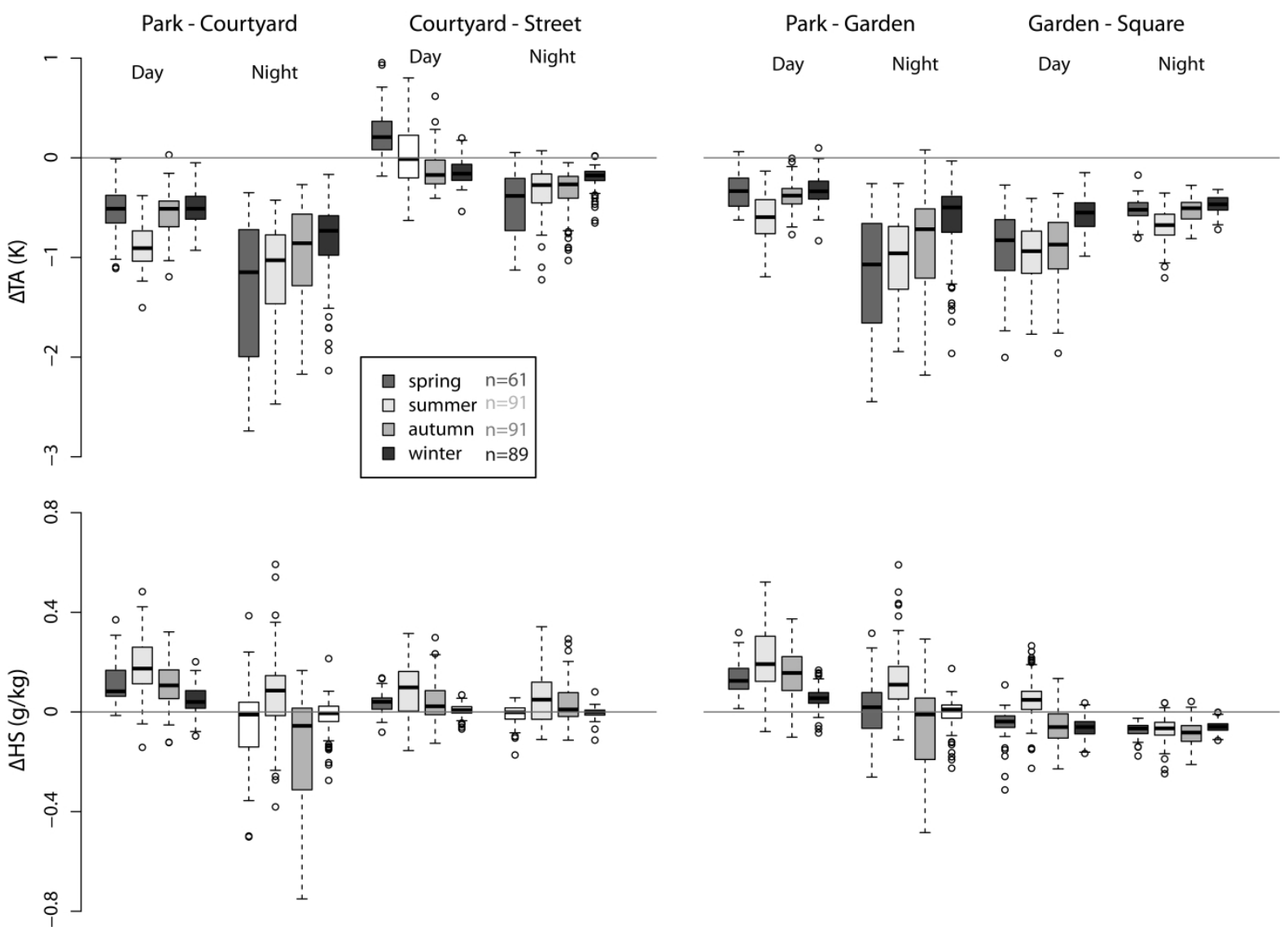

Figure 5. Boxplots of seasonal differences in air temperature (TA, top) and specific humidity (HS, bottom) between urban sites in Mainz. Boxes show 25-75 percentile, lines indicate the median, whiskers extend to approximately 5-95 percentile, and circles show outliers. Unfilled boxes are shown when sites are not significantly different. Results for spring, summer, autumn and winter are shown.

280 We found stronger cooling of the more vegetated sites during periods of increased transpiration. However,

281 this relationship varied between daytime and nighttime and with respect to the surrounding architectural structures (Fig. 6). The association between $\Delta \mathrm{TA}$ and $\Delta \mathrm{HS}$ generally revealed colder conditions to be associated 
283 with higher humidity, although the relationship varied among sites. The strongest relationship was found in

284 the differences between the enclosed Courtyard and adjacent Street, where a more humid Courtyard was also

285 colder than the street. For this site comparison, variation in $\triangle \mathrm{HS}$ could explain $73 \%$ of the variation in $\triangle T A$.

286 However, a weaker opposite relationship was also found, indicating that when the Courtyard during day-time

287 was more humid than the Street, it was also warmer. This was also found for the Park - Courtyard comparison

288 at night. For the remaining site comparisons, significant relationships were always negative. Significant

289 negative relationships were found between $\triangle T A$, and both MDS and SF, demonstrating that increased

290 transpiration generally results in an increased cooling of the more vegetated site. This effect is stronger in the

291 night than in the day. The colour coding based on day of year show slightly stronger SF in the later part of the

292 summer (lighter dots), especially in the nighttime data. This pattern does not affect the relationship between

293 SF and cooling. 


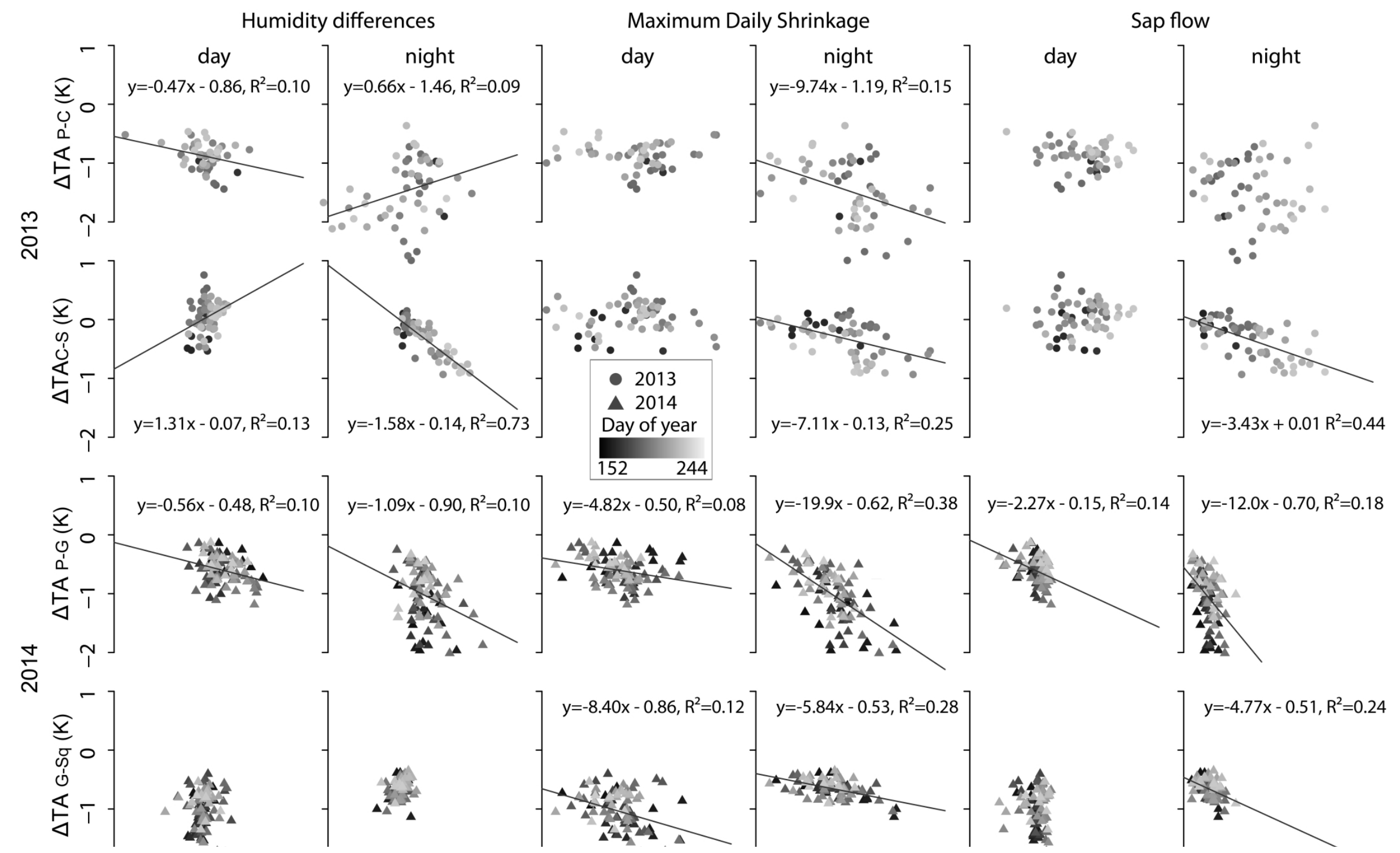

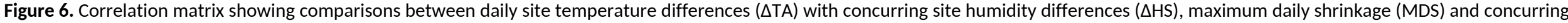
sap flux density (SF) during day and night (different columns). The MDS and SF values used here represent the urban sites (Courtyard/Garden). Data from the two summers are measured in the courtyard (2013, circles) and Garden (2014, triangles) and grey scale colour coded based on day of year. Regression lines of the corresponding linear models are included if $p<0.01$. 
The categorization of summer days with respect to evaporative demand - an important driver for tree transpiration - emphasizes the link between sites $\triangle T A$ and VPD (Fig. 7). The $\triangle T A$ between the Park and the urban sites generally increased with increasing VPD reaching a maximum at night. The only exception was the courtyard that is not significantly different during daytime from the less vegetated street. The drier category (VPD ${ }_{\text {Hdry }}$ ) indicated an increased cooling in the courtyard relative to both Park and Street, compared to the wet days ( $\left(\mathrm{PD}_{\text {Hwet }}\right)$. The general weather conditions during $\mathrm{VPD}_{\text {Hdry }}$ were on average slightly less windy $(1.8 \mathrm{~m} / \mathrm{s}$ vs $2.0 \mathrm{~m} / \mathrm{s}$ for $V_{P D} D_{\text {Hwet }}$ ) and had higher average VPD (2.2 $\mathrm{kPa}$ vs $1.9 \mathrm{kPa}$ for $\left.\mathrm{VPD}_{\text {Hwet }}\right)$. The vegetated sites were also more humid, with the exception for nocturnal Garden - Square comparison, where the vegetated garden was less humid compared to the very sparsely vegetated square.

$\Delta \mathrm{TA}$ $\Delta \mathrm{HS}$
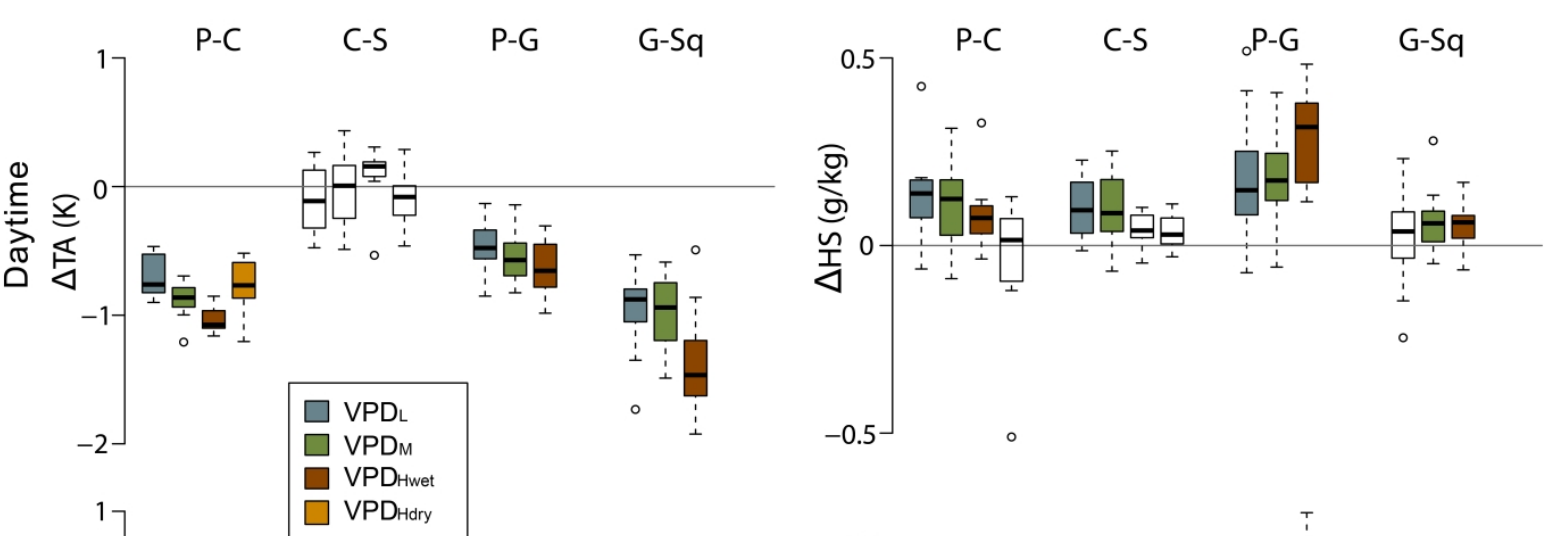

306
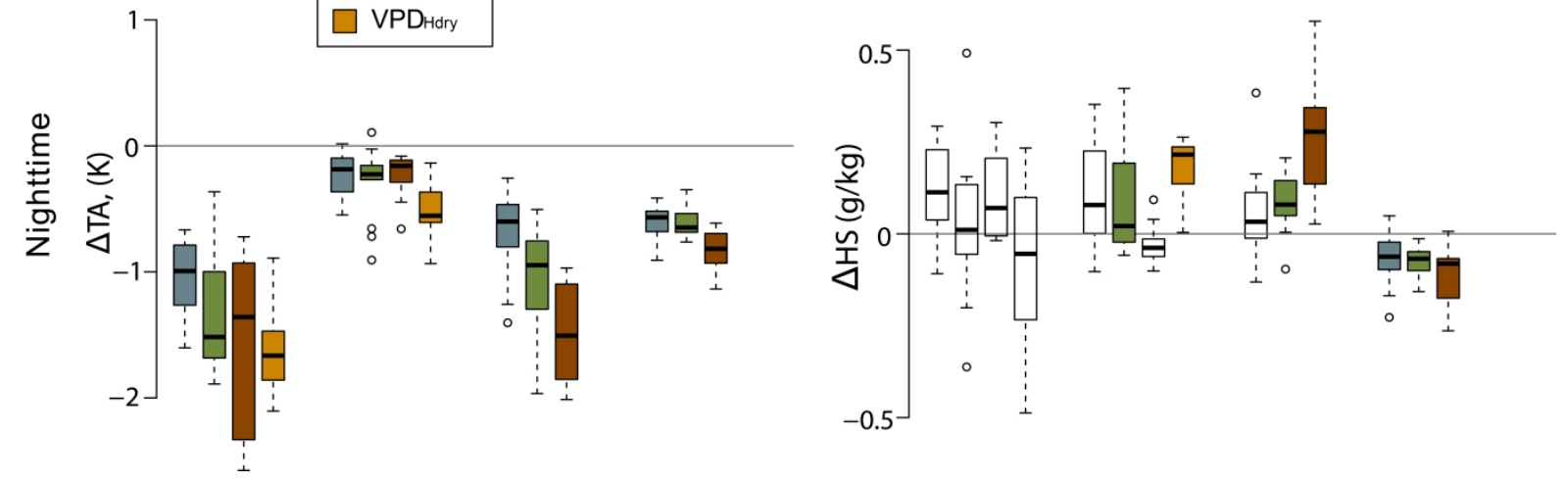

Figure 7. Boxplots showing the variations in day (top) and night (bottom) $\triangle T A$ (left) and $\triangle H S$ (right) for the four categories of transpiration demand; low VPD (VPD $)$, medium VPD (VPD $)$, high VPD, wet (VPD Hwet $_{\text {Het }}$ ), and high VPD, dry $\left(\mathrm{VPD}_{\text {Hdry }}\right)$. Data from the 2013 (Park - Courtyard and Courtyard - Street comparison, n=7/34/10/8 for the different categories) and 2014 (Park - Garden and Garden - Square comparison, n=27/54/11/0) summers are used. Boxes show 25-75 percentile, with lines across the median. Whiskers indicate the 5-95 percentile and circles show outliers. Unfilled boxes indicate that the compared sites were not significantly different $(p<0.01)$

\section{Discussion}

In this study we show that transpiration-induced cooling from urban trees is important for the development of microclimatic differences in a mid-size (200.000 inhabitant) city like Mainz. The cooling effects show seasonal 
and diurnal variations, as well as sensitivity to the surrounding urban geometry and weather conditions. In the following sections we will discuss the magnitude and temporal variability of this cooling effect, and address the significance of urban geometry, weather, and water availability.

\subsection{Link between microclimate cooling and transpiration}

An urban heat island effect was found in the center of Mainz throughout the two examined years, with magnitudes similar to that reported from other cities in Germany, e.g. Krefeld (Blankenstein and Kuttler 2004) and Trier (Junk et al. 2003). Although the urban heat island effect was largest in spring, the urban vegetated sites were cooler and more humid relative to the adjacent sparsely vegetated urban sites during the summer. A stronger cooling was also linked to a higher ambient humidity of the vegetated sites relative to their coupled sparsely vegetated sites, indicating evapotranspiration cooling as the cause for the temperature differences, as also found by Hamada and Ohta (2010). Furthermore, our findings indicate that the influence of tree transpiration, as deduced from SF and MDS, is also significantly linked to a stronger cooling. As direct measurements of transpiration, for example through measurements of leaf gas exchange, are labour intense and expensive, estimation of transpiration from SF has been used in several studies (e.g. Daley and Phillips 2006; Dawson et al. 2007; Granier et al. 1996) and the significant relationships to temperature differences found here indicate that measurements of SF can also be used for assessing the transpiration-induced cooling. There are, however, several variations in this pattern that need to be addressed. Transpiration induced cooling is most pronounced during the nighttime when transpiration is generally considered to be insignificant as stomata are thought to be close (Berninger et al. 1996; Cowan and Farquhar 1977; Hari et al. 1986). However, a stronger nocturnal cooling in vegetated sites has also been found in other studies (Bowler et al. 2011; Holmer et al. 2013; Lindén 2011; Qiu et al. 2013; Spronken-Smith and Oke 1998). In addition, it has been demonstrated that the stomata of many tree species remain partially open at night (Alvarado-Barrientos et al. 2015; Barbour et al. 2005; Bucci et al. 2004; Cavender-Bares and Bazzaz 2000; Dawson et al. 2007; Grulke et al. 2004; Matyssek et al. 1995; Scholz et al. 2007; Snyder et al. 2003). Nocturnal SF and transpiration has been documented in other studies (Daley and Phillips 2006; Dawson et al. 2007; Fisher et al. 2007; Konarska 2016; Marks and Lechowicz 2007; Moore et al. 2008; Rosado et al. 2012; Scholz et al. 2007; Snyder et al. 2003; Zeppel et al. 2010) and quantified to reach 5-40\% of the daytime levels (Caird et al. 2007). In single sites, night transpirations of up to $50 \%$ of day maximum has been reported (Matyssek et al. 1995). Our results are thus in line with evidence summarized in the review by Zeppel et al. (2014) indicating that wide range of ecosystems may lose substantial amounts of water at night. Although it remains unclear how much of the nocturnal SF is indeed transpired and how much is used for refilling of the stem and embolism repair (Zeppel et al. 2014), other work indicated that 50-95\% of the nocturnal SF is lost through transpiration from the canopy (AlvaradoBarrientos et al. 2015; Moore et al. 2008; Zeppel et al. 2010). The indication of an increase in nocturnal transpiration in the later part of the summers could be caused by a reduced ability to prevent water loss due to aging of the leaves, as described by for example Raschke and Zeewart (1976) and Wilson et al (2000). Zhou et al (2015) found that the temperature response in dark respiration was affected by the age of the leaves. 
However, the variation in levels of SF throughout the summer, did not affect the microclimate influence where a stronger SF was linked to a stronger cooling.

356 These findings support our observations that a substantial fraction of the total tree transpiration occurred

357 during nighttime, potentially reaching up to one third of daytime levels in the city of Mainz (Figure 4). This

358 fraction alone does, however, not explain why transpiration-induced cooling is most pronounced at night. A

359 similar pattern was reported by Konarska et al (2016) who show that although the latent heat flux from

360 nocturnal transpiration cooling in Gothenburg, Sweden, was estimated to around $12 \%$ of that at midday, a

361 cooling effect was only observed around and shortly after sunset. Stronger nighttime cooling in Gothenburg

362 was attributed to a lower nocturnal atmospheric mixing, a phenomenon that is well known from many sites

363 (e.g. Eliasson and Holmer 1990). Liu and Liang (2010) showed that the boundary layer, where mixing occurs,

364 reaches a nocturnal height of about $15 \%$ of the daytime, due a stabilizing of the nocturnal surface layer

365 because of infrared radiative cooling, while solar heating causes convective unstable conditions in the daytime.

366 Although the height of the boundary layer is generally increased over urban areas (Oke 1982), dispersion of

367 the air cooled by nocturnal transpiration would be considerably restricted at night, supporting indications that

368 the limited nocturnal transpiration is an important cooling factor in urban climate.

\subsection{Impact of urban geometry}

As urban structure can prevent ventilation by obstructing winds (e.g. Oke 1987), and thus favour microclimate differences, the most pronounced transpiration-induced cooling is recorded in the enclosed courtyard where ventilation is limited. As courtyards are common in urban environments, the substantial cooling of just a few trees as reported here appears critical to this type of environment. Taleghani et al. (2014) showed that also ground vegetation and ponds cool temperatures and increase comfort in courtyards, though their study focused on daytime effects. The more open geometry and sloping ground of the examined garden allows for dispersion of the cooled air thus preventing strong correlations with transpiration cooling. Furthermore, a downhill flow of cooled air during stable nocturnal conditions (Bigg et al. 2014), from the garden towards the Square, could explain both the reduced nocturnal TA differences as well as the higher humidity levels in the sparsely vegetated Square.

The weaker, and partly opposite, relationship (i.e., increased humidity and temperature in the courtyard, compared to the street) during daytime, may be caused by a reversed influence where a stronger heating of the urban materials raises TA and thus increases evaporative demand and transpiration. This process might counteract the transpiration cooling and hinder the statistical validation of daytime transpiration cooling effects. Furthermore, the high daytime spring temperatures in the courtyard, mainly measured before the trees were foliated, provides good indication that without shading and transpiration from the trees, the courtyard would be considerably warmer. While heat stress is highest during daytime, when tree shading is known to considerably increase the level of comfort (Emmanuel et al. 2007; Konarska et al. 2014; Lee 2013; 
mortality during heat waves (Clarke 1972; Conti et al. 2005). The nocturnal transpiration cooling reported in this study is thus of great importance for the well-being of the urban inhabitants.

\subsection{Influence of evaporative demand and drought on transpiration cooling}

As reported in other studies (e.g. Eamus et al. 2013), increased evaporative demand (VPD), i.e. warmer temperatures and reduced humidity, resulted in increased transpiration in Mainz. Our analysis shows that this dependency is reflected in the transpiration-induced cooling as well. While transpiration-induced cooling increases thermal comfort, the increased humidity caused by the transpiration could likewise decrease comfort. However, this effect was not found to be relevant for human heat stress in the similar climate of Freiburg, Germany (Lee et al. 2016).

We here showed that dry conditions as observed within our monitoring period only caused slight sap flow reductions in the courtyard during day, and an increase during night. Decoupling of midday transpiration under drought as a water saving behaviour has previously been observed in tropical (Brodribb and Holbrook 2004; Gindaba et al. 2004; Kosugi et al. 2009) and temperate trees (Kamakura et al. 2012). However, no reduction in MDS during drought was found in our study. Furthermore, during dry conditions the transpiration-induced cooling in the courtyard appeared considerably stronger at night, but also slightly stronger during daytime, compared to when water availability was higher. If daytime transpiration was reduced for water saving purposes, cooling should not be stronger at this time. This indicates that the examined trees did not suffer from drought stress in the examined conditions, which could be due to that the main species in this study, Platanus $x$ acerifolia, is known to be drought tolerant (e.g. Bowden et al 2008) or that its root system had continuous access to water. In a study by Gillner et al (2015) the leaf gas exchange rate of Platanus $x$ acerifolia was found to be significantly higher compared to Tilia platyphyllos and Acer platanoides, especially during periods of high VPD. Although no indications of species-specific differences in MDS were found in this study, considerable differences in transpiration between species has been found (e.g. Dawson et al. 2007; Gillner et al. 2015), and the nocturnal transpiration-induced cooling of different species needs to be further examined. The shape of the individual trees used for installing temperature sensors could potentially affect the temperature patterns as differences in canopy geometry canopy has been found to influence below-canopy temperatures (Lin and Lin 2010). However, the canopy geometry of street trees often differ from that of park and garden trees by necessity as it has to be shaped not to obstruct activity such as traffic. The potential influence of canopy geometry is therefore likely to reflect the general influence of urban trees.

It should be noted that slightly different wind and VPD conditions during the dry and wet categories might impact the cooling effects. The influence of drought on the transpiration-induced urban cooling thus needs to be studied further to improve our understanding of how trees would affect the microclimate in a warming world.

\section{Conclusion}


In this study we show that transpiration-induced cooling from trees is an important driver of intra-urban differences in a 200.000 inhabitant city in Germany. The cooling effect explains a considerable fraction of spatial temperature variations in summer, particularly during night and in a framed courtyard environment. As the observed nighttime transpiration is lower compared to daytime, the overall stronger nighttime cooling signal is attributed to the limited dispersion of cooled air in the stable nocturnal atmospheric conditions. We also show that transpiration-induced cooling increase with atmospheric evaporative demand. Whereas indications of changing temperature pattern during drought stress were found, the impact of sustained drought on urban trees and environments needs to be further investigated.

These findings show that even a few trees can make a significant difference in urban environments and thus represent a suitable tool to mitigate excessive urban heat when planning for a warmer future climate. However, in order to maximize heat mitigation through tree transpiration, it is important to carefully consider how variation of atmospheric evaporative demand and surrounding geometry impact the diurnal and seasonal variations of the cooling effect.

\section{Acknowledgement}

We are grateful to Birgit Heide from the Landesmuseum and Hendrik Maskus from the Altmünstergemeinde in Mainz who allowed us to set up instrumentation on their property, and to their co-workers who supported us in the field, as well as the City of Mainz for being helpful in finding suitable locations for street side measurements. We thank Berthold Friederich for supplying data from meteorological station of the Institute of Atmospheric Physics at Johannes Gutenberg University.

\section{References}

Alavipanah, S., M. Wegmann, S. Qureshi, Q. Weng, and T. Koellner, 2015: The Role of Vegetation in Mitigating Urban Land Surface Temperatures: A Case Study of Munich, Germany during the Warm Season. Sustainability, 7, 4689-4706.

Alvarado-Barrientos, M. S., F. Holwerda, D. Geissert, L. Muñoz-Villers, S. Gotsch, H. Asbjornsen, and T. Dawson, 2015: Nighttime transpiration in a seasonally dry tropical montane cloud forest environment. Trees, 29, 259-274.

Arnfield, A. J., 2003: Two decades of urban climate research: A review of turbulence, exchanges of energy and water, and the urban heat island. International Journal of Climatology, 23, 1-26.

Barbour, M. M., L. A. Cernusak, D. Whitehead, K. L. Griffin, M. H. Turnbull, D. T. Tissue, and G. D. Farquhar, 2005: Nocturnal stomatal conductance and implications for modelling delta O-18 of leafrespired $\mathrm{CO} 2$ in temperate tree species. Functional Plant Biology, 32, 1107-1121.

Berninger, F., A. Makela, and P. Hari, 1996: Optimal control of gas exchange during drought: Empirical evidence. Annals of Botany, 77, 469-476. Bigg, G. R., S. M. Wise, E. Hanna, D. Mansell, R. G. Bryant, and A. Howard, 2014: Synoptic climatology of cold air drainage in the Derwent Valley, Peak District, UK. Meteorol. Appl., 21, 161-170. 
Blankenstein, S., and W. Kuttler, 2004: Impact of street geometry on downward longwave radiation and air temperature in an urban environment. Meteorologische Zeitschrift, 13, 373-379. Bowler, D. E., L. Buyung-Ali, T. M. Knight, and A. S. Pullin, 2011: Urban greening to cool towns and cities: A systematic review of the empirical evidence. Landscape and Urban Planning, 97, 147-155. Brodribb, T. J., and N. M. Holbrook, 2004: Diurnal depression of leaf hydraulic conductance in a tropical tree species. Plant Cell and Environment, 27, 820-827.

Bucci, S. J., F. G. Scholz, G. Goldstein, F. C. Meinzer, J. A. Hinojosa, W. A. Hoffmann, and A. C. Franco, 2004: Processes preventing nocturnal equilibration between leaf and soil water potential in tropical savanna woody species. Tree Physiology, 24, 1119-1127.

Bush, S. E., Pataki D.E., Hultine K.R, West A.G., Sperry J.S., and E. J.R., 2008: Wood anatomy constrains stomatal responses to atmospheric vapor pressure deficit in irrigated, urban trees. Physiolgical Ecology.

Caird, M. A., J. H. Richards, and L. A. Donovan, 2007: Nighttime stomatal conductance and transpiration in C-3 and C-4 plants. Plant Physiology, 143, 4-10.

Cavender-Bares, J., and F. A. Bazzaz, 2000: Changes in drought response strategies with ontogeny in Quercus rubra: implications for scaling from seedlings to mature trees. Oecologia, 124, 8-18. Clarke, J. F., 1972: SOME EFFECTS OF URBAN STRUCTURE ON HEAT MORTALITY. Environmental Research, 5, 93-\&.

Conti, S., and Coauthors, 2005: Epiderniologic study of mortality during the Summer 2003 heat wave in Italy. Environmental Research, 98, 390-399.

Cowan, I. R., and G. D. Farquhar, 1977: Stomatal function in relation to leaf metabolism and environment. Symposia of the Society for Experimental Biology, 31, 471-505.

Da Cunha, A. R., 2015: Evaluation of measurement errors of temperature and relative humidity from HOBO data logger under different conditions of exposure to solar radiation. Environmental monitoring and assessment, 187, 1-11.

Daley, M. J., and N. G. Phillips, 2006: Interspecific variation in nighttime transpiration and stomatal conductance in a mixed New England deciduous forest. Tree Physiology, 26, 411-419.

Dawson, T. E., and Coauthors, 2007: Nighttime transpiration in woody plants from contrasting ecosystems. Tree Physiology, 27, 561-575.

Eamus, D., N. Boulain, J. Cleverly, and D. D. Breshears, 2013: Global change-type drought-induced tree mortality: vapor pressure deficit is more important than temperature per se in causing decline in tree health. Ecology and Evolution, 3, 2711-2729.

Eliasson, I., and B. Holmer, 1990: Urban Heat Island Circulation in Göteborg, Sweden. Theoretical and Applied Climatology, 42, 187-196.

Emmanuel, R., H. Rosenlund, and E. Johansson, 2007: Urban shading - a design option for the tropics? A study in Colombo, Sri Lanka. International Journal of Climatology, 27, 1995-2004.

Fan, C., S. W. Myint, and B. Zheng, 2015: Measuring the spatial arrangement of urban vegetation and its impacts on seasonal surface temperatures. Progress in Physical Geography, 39, 199-219.

Fisher, J. B., D. D. Baldocchi, L. Misson, T. E. Dawson, and A. H. Goldstein, 2007: What the towers don't see at night: nocturnal sap flow in trees and shrubs at two AmeriFlux sites in California. Tree Physiology, 27, 597-610.

Gao, Q., P. Zhao, X. Zeng, X. Cai, and W. Shen, 2002: A model of stomatal conductance to quantify the relationship between leaf transpiration, microclimate and soil water stress. Plant, Cell and Environment, 25, 1373-1381.

Gillner, S., S. Korn, and A. Roloff, 2015: Leaf-Gas Exchange of Five Tree Species at Urban Street Sites. Arboriculture \& Urban Forestry, 41.

Gindaba, J., A. Rozanov, and L. Negash, 2004: Response of seedlings of two Eucalyptus and three deciduous tree species from Ethiopia to severe water stress. Forest Ecology and Management, 201, 121-131.

Granier, A., 1987: SAP FLOW MEASUREMENTS IN DOUGLAS-FIR TREE TRUNKS BY MEANS OF A NEW THERMAL METHOD. Annales Des Sciences Forestieres, 44, 1-14. 

forest stands: short and long-term monitoring using sapflow methods. Global Change Biology, 2, 265-274.

517 Grimmond, C. S. B., and T. R. Oke, 1991: AN EVAPOTRANSPIRATION-INTERCEPTION MODEL FOR URBAN AREAS. Water Resources Research, 27, 1739-1755. pole-sized and mature ponderosa pine: implications for O-3 exposure metrics. Tree Physiology, 24, 1001-1010.

Hamada, S., and T. Ohta, 2010: Seasonal variations in the cooling effect of urban green areas on surrounding urban areas. Urban Forestry \& Urban Greening, 9, 15-24.

Hari, P., A. Maekelae, E. Korpilahti, and M. Holmberg, 1986: Optimal control of gas exchange. Tree Physiology, 2, 169-175.

Harlan, S. L., A. J. Brazel, L. Prashad, W. L. Stefanov, and L. Larsen, 2006: Neighborhood microclimates and vulnerability to heat stress. Social Science \& Medicine, 63, 2847-2863. Hipps, N. A., M. J. Davies, J. M. Dunn, H. Griffiths, and C. J. Atkinson, 2014: Effects of two contrasting canopy manipulations on growth and water use of London plane (Platanus $\mathrm{x}$ acerifolia) trees. Plant and Soil, 382, 61-74.

Holmer, B., S. Thorsson, and J. Lindén, 2013: Evening evapotranspirative cooling in relation to vegetation and urban geometry in the city of Ouagadougou, Burkina Faso. International Journal of Climatology, 33, 3089-3105.

IPCC, 2014: Fifth Assessment Report: Climate Change 2014.

Jonsson, P., 2004: Vegetation as an urban climate control in the subtropical city of Gaborone, Botswana. International Journal of Climatology 24, 1307-1322

Junk, J., A. Helbig, and J. Lüers, 2003: Urban climate and air quality in Trier Germany. international journal of Biometeorology, 47, 230-238.

Kamakura, M., Y. Kosugi, S. Takanashi, H. Tobita, A. Uemura, and H. Utsugi, 2012: Observation of the scale of patchy stomatal behavior in leaves of Quercus crispula using an Imaging-PAM chlorophyll fluorometer. Tree Physiology, 32, 839-846.

King, G., P. Fonti, D. Nievergelt, U. Buentgen, and D. Frank, 2013: Climatic drivers of hourly to yearly tree radius variations along a 6 degrees $C$ natural warming gradient. Agricultural and Forest Meteorology, 168, 36-46.

Konarska, J., F. Lindberg, A. Larsson, S. Thorsson, and B. Holmer, 2014: Transmissivity of solar radiation through crowns of single urban trees-application for outdoor thermal comfort modelling. Theoretical and Applied Climatology, 117, 363-376.

Konarska, J., J. Uddling, B. Holmer, M. Lutz, F. Lindberg, H. Pleijel, and S. Thorsson, 2016: Transpiration of urban trees and its cooling effect in a high latitude city. International journal of biometeorology, 60, 159-172.

Konarska, J., Uddling, J.,Holmer, B., Lutz, M., Lindberg, F., Pleijel, H., Thorsson, S., 2016: Transpiration of urban trees and its cooling effect in a high latitude city. International Journal of Biometeorology, 60, 159-172.

Kosugi, Y., S. Takanashi, N. Matsuo, and A. R. Nik, 2009: Midday depression of leaf CO2 exchange within the crown of Dipterocarpus sublamellatus in a lowland dipterocarp forest in Peninsular Malaysia. Tree Physiology, 29, 505-515.

Lee, H., H. Mayer, and L. Chen, 2016: Contribution of trees and grasslands to the mitigation of human heat stress in a residential district of Freiburg, Southwest Germany. Landscape and Urban Planning, 148, 37-50.

Lee, H., Holst, J., Mayer, H., 2013: Modification of Human-Biometeorologically Significant Radiant Flux Densities by Shading as Local Method to Mitigate Heat Stress in Summer within Urban Street Canyons. Advances in Meteorology. Lin, B.-S., and Y.-J. Lin, 2010: Cooling effect of shade trees with different characteristics in a subtropical urban park. HortScience, 45, 83-86. 
Lindén, J., 2011: Nocturnal Cool Island in the Sahelian city of Ouagadougou, Burkina Faso. International Journal of Climatology, 31, 605-620. Liu, S., and X.-Z. Liang, 2010: Observed Diurnal Cycle Climatology of Planetary Boundary Layer Height. Journal of Climate, 23, 5790-5809. Ma, C. C., Y. B. Gao, H. Y. Guo, and J. L. Wang, 2004: Photosynthesis, Transpiration, and Water Use Efficiency of Caragana microphylla, C. intermedia, and C. korshinskii. Photosynthetica, 42, 65-70. Marks, C. O., and M. J. Lechowicz, 2007: The ecological and functional correlates of nocturnal transpiration. Tree Physiology, 27, 577-584.

Matyssek, R., M. S. Gunthardtgoerg, S. Maurer, and T. Keller, 1995: NIGHTTIME EXPOSURE TO OZONE REDUCES WHOLE-PLANT PRODUCTION IN BETULA-PENDULA. Tree Physiology, 15, 159-165. Middel, A., A. J. Brazel, P. Gober, S. W. Myint, H. Chang, and J.-D. Duh, 2012: Land cover, climate, and the summer surface energy balance in Phoenix, AZ, and Portland, OR. International Journal of Climatology, 32, 2020-2032.

Monteith, J., and M. Unsworth, 2007: Principles of environmental physics. Academic Press. Moore, G. W., J. R. Cleverly, and M. K. Owens, 2008: Nocturnal transpiration in riparian Tamarix thickets authenticated by sap flux, eddy covariance and leaf gas exchange measurements. Tree Physiology, 28, 521-528.

Mueller, E. C., and T. A. Day, 2005: The effect of urban ground cover on microclimate, growth and leaf gas exchange of oleander in Phoenix, Arizona. International Journal of Biometeorology, 49, 244255.

Norton, B. A., A. M. Coutts, S. J. Livesley, R. J. Harris, A. M. Hunter, and N. S. G. Williams, 2015: Planning for cooler cities: A framework to prioritise green infrastructure to mitigate high temperatures in urban landscapes. Landscape and Urban Planning, 134, 127-138.

Oke, T., 2008: Urban observations. Guide to meteorological instruments and methods of observation, Part II of Observing Systems, WMO-No. 8.

Oke, T. R., 1982: THE ENERGETIC BASIS OF THE URBAN HEAT-ISLAND. Quarterly journal of the Royal Meteorological Society, 108, 1-24.

Oke, T. R., 1987: Boundary Layer Climates 2ed. Routledge Oliveira, A. P. B., R.D.; Soares, J., 2002: Annual and Diurnal Wind Patterns in the City of Sao Paulo. Water, Air, \& Soil Pollution: Focus, 3, 3-15.

Oliveira, S., H. Andrade, and T. Vaz, 2011: The cooling effect of green spaces as a contribution to the mitigation of urban heat: A case study in Lisbon. Building and Environment, 46, 2186-2194.

Pataki, D. E., H. R. McCarthy, E. Litvak, and S. Pincetl, 2011: Transpiration of urban forests in the Los Angeles metropolitan area. Ecological Applications, 21, 661-677.

Potchter, O., P. Cohen, and A. Bitan, 2006: Climatic behavior of various urban parks during hot and humid summer in the Mediterranean city of Tel Aviv, Israel International Journal of Climatology 26, 1695-1711

Qiu, G.-y., H.-y. Li, Q.-t. Zhang, W. Chen, X.-j. Liang, and X.-z. Li, 2013: Effects of Evapotranspiration on Mitigation of Urban Temperature by Vegetation and Urban Agriculture. Journal of Integrative Agriculture, 12, 1307-1315.

Raschke, K., and J. A. Zeevaart, 1976: Abscisic acid content, transpiration, and stomatal conductance as related to leaf age in plants of Xanthium strumarium L. Plant Physiology, 58, 169-174.

Rosado, B. H. P., R. S. Oliveira, C. A. Joly, M. P. M. Aidar, and S. S. O. Burgess, 2012: Diversity in nighttime transpiration behavior of woody species of the Atlantic Rain Forest, Brazil. Agricultural and Forest Meteorology, 158, 13-20.

Scholz, F. G., S. J. Bucci, G. Goldstein, F. C. Meinzer, A. C. Franco, and F. Miralles-Wilhelm, 2007: Removal of nutrient limitations by long-term fertilization decreases nocturnal water loss in savanna trees. Tree Physiology, 27, 551-559.

Snyder, K. A., J. H. Richards, and L. A. Donovan, 2003: Night-time conductance in C-3 and C-4 species: do plants lose water at night? Journal of Experimental Botany, 54, 861-865. 
615 Spronken-Smith, R. A., and T. R. Oke, 1998: The thermal regime of urban parks in two cities with 616 different summer climates. International Journal of Remote Sensing, 19, 2085-2104.

617 Stewart, I. D., and T. R. Oke, 2012: LOCAL CLIMATE ZONES FOR URBAN TEMPERATURE STUDIES.

618 Bulletin of the American Meteorological Society, 93, 1879-1900.

619 Taha, H., 1997: Urban climates and heat islands: albedo, evapotranspiration, and anthropogenic 620 heat. Energy and Buildings, 25, 99-103.

621 Taleghani, M., M. Tenpierik, A. van den Dobbelsteen, and D. J. Sailor, 2014: Heat in courtyards: A 622 validated and calibrated parametric study of heat mitigation strategies for urban courtyards in the 623 Netherlands. Solar Energy, 103, 108-124.

624 Wilson, K. B., D. D. Baldocchi, and P. J. Hanson, 2000: Spatial and seasonal variability of 625 photosynthetic parameters and their relationship to leaf nitrogen in a deciduous forest. Tree 626 Physiology, 20, 565-578.

627 Wong, N. H., Y. Chen, C. L. Ong, and A. Sia, 2003: Investigation of thermal benefits of rooftop garden

628 in the tropical environment. Building and environment, 38, 261-270.

629 Zeppel, M., D. Tissue, D. Taylor, C. Macinnis-Ng, and D. Eamus, 2010: Rates of nocturnal

630 transpiration in two evergreen temperate woodland species with differing water-use strategies. Tree

631 Physiology, 30, 988-1000.

632 Zeppel, M. J. B., J. D. Lewis, N. G. Phillips, and D. T. Tissue, 2014: Consequences of nocturnal water 633 loss: a synthesis of regulating factors and implications for capacitance, embolism and use in models. 634 Tree Physiology, 34, 1047-1055.

635 Zhou, H., M. Xu, H. Pan, and X. Yu, 2015: Leaf-age effects on temperature responses of 636 photosynthesis and respiration of an alpine oak, Quercus aquifolioides, in southwestern China. Tree 637 physiology, tpv101.

638 Zweifel, R., H. Item, and R. Hasler, 2001: Link between diurnal stem radius changes and tree water 639 relations. Tree Physiology, 21, 869-877. 